\title{
A Álgebra e seu papel: reflexões a partir das produções do GT 04 da SBEM
}

\author{
Algebra and its role: reflections based on the works of SBEM GT04
}

Barbara Lutaif Bianchini*

ORCID iD 0000-0003-0388-1985

Gabriel Loureiro de Lima**

ORCID iD 0000-0002-5723-0582

\begin{abstract}
Resumo
Neste artigo, apresenta-se parte dos resultados de uma análise interpretativa, realizada adotando-se como corpus cinco pesquisas sobre a temática Álgebra, desenvolvidas por integrantes do Grupo de Trabalho Educação Matemática no Ensino Superior (GT04), filiado à Sociedade Brasileira de Educação Matemática (SBEM). Para coleta, categorização e análise dos dados, recorre-se a preceitos da Análise de Conteúdo na concepção de Bardin. Foram construídas cinco categorias de análise e, neste artigo, duas delas são analisadas: C1: O que é Álgebra? e C2: O papel da Álgebra. Para cada categoria, além de apresentarem-se as reflexões presentes nos trabalhos analisados, estabelecem-se diálogos entre tais reflexões e outras evidenciadas em pesquisas de referência na Educação Algébrica. Em relação à categoria $\mathrm{C} 1$, os dados explicitam que respostas à questão $\mathrm{O}$ que é Álgebra? contemplam aspectos históricos, estruturais, relacionados à generalização, a conteúdos e a notações normalmente associados à Álgebra, à relação entre Aritmética e Álgebra e à permeabilidade da Álgebra em diferentes campos da Matemática e distintas áreas de conhecimento. Já a respeito da categoria $\mathrm{C} 2$, os resultados indicam que a Álgebra desempenha papéis tanto para a construção do conhecimento matemático do estudante, quanto para a formação do professor que irá mediar esse processo de construção em sala de aula, estando tais papéis vinculados ao conhecimento das estruturas, das demonstrações, do simbolismo, à centralidade das generalizações e à apropriação da linguagem e do pensamento algébrico para o sujeito pensar e se comunicar matematicamente.
\end{abstract}

Palavras-chave: O que é Álgebra. O papel da Álgebra. Grupo de Trabalho Educação Matemática no Ensino Superior. Sociedade Brasileira de Educação Matemática. Análise Interpretativa.

\begin{abstract}
In this article, we present part of the results of an interpretative analysis carried out adopting as corpus of work five studies on the Algebra subject, developed by members of the Working Group for Mathematical Education in Higher Education (GT04), linked to the Brazilian Society of Mathematical Education (SBEM). To collect, categorize, and analyze the data, we consulted precepts of Content Analysis in the conception of Bardin. Five categories of analysis were built and this article focused on two: $\mathrm{C} 1$ : What is Algebra? and C2: The role of Algebra. For each category, in addition to presenting the reflections present in the analyzed works, we established dialogues among these considerations and others presented in the reference studies in Algebraic Education. Regarding C1, the data highlights that answers to the question What is Algebra? contemplates historical and structural aspects related to generalization, contents, and observations commonly associated to Algebra, the relation between Arithmetic and Algebra, and the permeability of Algebra in different fields of Mathematics and knowledge. As for

\footnotetext{
* Doutora em Educação (Psicologia da Educação pela Pontifícia Universidade Católica de São Paulo (PUC). Professora do Programa de Estudos Pós-Graduados em Educação Matemática da Pontifícia Universidade Católica de São Paulo (PUC), São Paulo, São Paulo, Brasil. E-mail: barbara @ pucsp.br.

** Doutor em Educação Matemátca pela Pontifícia Universidade Católica de São Paulo (PUC). Professor do Programa de Estudos Pós-Graduados em Educação Matemática da Pontifícia Universidade Católica de São Paulo (PUC), São Paulo, São Paulo, Brasil. E-mail: gllima@pucsp.br.
} 
category $\mathrm{C} 2$, the results point to the fact that Algebra plays a role in the construction of mathematical knowledge, as well as in the teacher's work, who will mediate this construction process in the classroom. These roles are linked to the knowledge of structures, demonstrations, symbolism, the centrality of generalizations, and the appropriation of the algebraic language and thought to enable the person to think and communicate mathematically.

Keywords: What is Algebra. The role of Algebra. Work Group Mathematical Education in Higher Education. Interpretative Analysis.

\section{Introdução}

Desde 2017, buscamos analisar as principais produções do Grupo de Trabalho Educação Matemática no Ensino Superior - GT04 da Sociedade Brasileira de Educação Matemática - SBEM, a partir de sua criação em 2000. O principal lócus de discussão do referido GT ocorre nas reuniões trienais do Grupo, durante as edições do Seminário Internacional de Pesquisa em Educação Matemática (SIPEM). Até o presente momento, houve sete edições desse Seminário (2000, 2003, 2006, 2009, 2012, 2015, 2018). Para as análises que desenvolvemos das produções do Grupo, tomamos como referência os artigos apresentados e discutidos nos SIPEM e as pesquisas deles decorrentes, que são explicitadas na próxima seção.

No ínterim do projeto de pesquisa, no qual estamos desenvolvendo mapeamentos e metanálises das investigações do GT04, até o presente momento, temos seis publicações: uma cujo foco foi Cálculo e Análise (LIMA; BIANCHINI; GOMES, 2017); duas contemplando, além dessas temáticas, também Álgebra Linear (BIANCHINI; LIMA; GOMES, 2018; BIANCHINI; LIMA; GOMES, 2019b); uma tratando exclusivamente das pesquisas do GT04 acerca de Álgebra Linear (LIMA; BIANCHINI; GOMES, 2019); uma publicação na qual articulamos produções do referido GT sobre Álgebra Linear em cursos de Engenharia com outras pesquisas latino-americanas sobre a temática, produzidas, entre 2007 e 2018, sob a chancela de sociedades de Educação Matemática com representatividade equivalente à da SBEM (BIANCHINI; LIMA; GOMES, 2019c); finalmente, uma investigação relativa à temática Formação de Professores (BIANCHINI; LIMA; GOMES, 2019a).

Dando continuidade a essa modalidade de investigação, optamos por realizar uma análise interpretativa, no sentido de Severino (2007), de cinco produções do GT04 referentes ao ensino e à aprendizagem de Álgebra, estabelecendo um diálogo entre tais produções e outras de referência na Educação Algébrica. Salientamos que não consideramos a temática Álgebra Linear, uma vez que esta já foi alvo de nossas investigações anteriores.

Como resultado dessa análise interpretativa, em cuja coleta, categorização e análise dos dados, utilizamos alguns pressupostos da Análise de Conteúdo na concepção de Bardin (2004), 
construímos cinco categorias de análise, a saber: C1 - O que é Álgebra?; C2 - O papel da Álgebra; C3 - Requisitos para aprender Álgebra; C4 - Como a Álgebra é ensinada e como deveria ser ensinada; C5 - Natureza das dificuldades evidenciadas na Aprendizagem de Álgebra. Neste artigo, restringimo-nos à apresentação das análises relativas às categorias $\mathrm{C} 1 \mathrm{e}$ C2. Na próxima seção, apresentamos a metodologia empregada em nossa pesquisa.

\section{Metodologia}

Como fontes de coleta de dados relativos às principais produções do GT04, consideramos: os anais das sete edições já realizadas do SIPEM, os artigos publicados nos livros Educação Matemática no Ensino Superior: pesquisas e debates (FROTA; NASSER, 2009) e Marcas da Educação Matemática no Ensino Superior (FROTA; BIANCHINI; CARVALHO, 2013), e, por fim, os artigos presentes nos números temáticos relativos ao GT04 das revistas Educação Matemática Pesquisa (volume 15, número 3, publicado em 2013) do Programa de Estudos Pós-Graduados em Educação Matemática (PEPGEM) da PUC-SP, Vidya (volume 37, número 2, publicado em 2017) do Programa de Pós-Graduação em Ensino de Ciências e Matemática da Universidade Franciscana, e Revista de Ensino de Ciências e Matemática (REnCiMa) (volume 10, número 2, editado em 2019) do Programa de Pós-Graduação em Ensino de Ciências e Matemática da Universidade Cruzeiro do Sul.

Realizadas as buscas nas fontes mencionadas, identificamos, a partir dos títulos e dos resumos, cinco pesquisas relacionadas ao ensino e à aprendizagem de Álgebra, desconsiderando as de Álgebra Linear, pelo motivo já exposto anteriormente. Inicialmente, tivemos acesso à íntegra apenas de dois dentre os cinco trabalhos; dos outros três, pudemos acessar apenas os resumos. Entramos em contato com os respectivos autores e solicitamos as versões completas dos artigos. Duas delas nos foram enviadas por e-mail e, quanto à terceira, a autora indicou um artigo completo, decorrente daquele que estávamos buscando, que havia sido publicado em uma revista científica.

Constituímos, dessa forma o corpus de análise com o qual trabalhamos no presente artigo, conforme evidencia o Quadro 1. 


\begin{tabular}{|c|c|c|}
\hline Título & Autores & Local e ano de publicação \\
\hline $\begin{array}{c}\text { Equações Algébricas nas práticas } \\
\text { vivenciadas: uma abordagem } \\
\text { histórica }\end{array}$ & $\begin{array}{c}\text { Angela Marta Pereira das Dores } \\
\text { Savioli }\end{array}$ & Anais do III SIPEM, 2006 \\
\hline $\begin{array}{c}\text { Origens e caracterizações da } \\
\text { álgebra e do pensamento algébrico } \\
\text { sob a ótica de vários autores }\end{array}$ & Angela Marta Pereira das Dores \\
Savioli & Anais do IV SIPEM, 2009 \\
\hline $\begin{array}{c}\text { A presença da Álgebra nos cursos } \\
\text { de Licenciatura em Matemática no } \\
\text { Estado do Rio Grande do Sul }\end{array}$ & $\begin{array}{c}\text { Fabiane Mondini e Maria } \\
\text { Aparecida Viggiani Bicudo }\end{array}$ & Acta Scientiae, v. 12, n. 2, \\
\hline $\begin{array}{c}\text { Set-befores e Met-befores: } \\
\text { polinômios }\end{array}$ & $\begin{array}{c}\text { Debora Cristiane Barbosa } \\
\text { Kirnev, Angela Marta Pereira } \\
\text { das Dores Savioli }\end{array}$ & Vidya, v. 37, n.2, 2017 \\
\hline $\begin{array}{c}\text { Indícios de dificuldade na } \\
\text { compreensão da matemática } \\
\text { avançada: o conceito de grupo }\end{array}$ & $\begin{array}{c}\text { Natássia Sachs Camerlengo de } \\
\text { Barbosa, Angela Marta Pereira } \\
\text { das Dores Savioli }\end{array}$ & Anais do V SIPEM, 2012 \\
\hline
\end{tabular}

Quadro 1 - Relação das pesquisas que fazem parte do corpus de análise

Fonte: dados da pesquisa

Para a coleta, categorização e análise dos dados, recorremos a pressupostos da Análise de Conteúdo, segundo Bardin (2004), metodologia que compreende: a pré-análise, a exploração do material e o tratamento e interpretação dos resultados obtidos. A pré-análise, de acordo com Bardin (2004, p. 89), "é a fase da organização propriamente dita [...] (e) tem por objetivo tornar operacionais e sistematizar as ideias iniciais, de maneira a conduzir a um esquema preciso do desenvolvimento das operações sucessivas, num plano de análise”. Engloba as ações: (i) a escolha dos materiais a serem analisados, (ii) a formulação de hipóteses e dos objetivos e (iii) a elaboração de indicadores que fundamentam a interpretação final.

Para este artigo, assumimos a priori que o corpus, definido por Bardin (2004, p. 90) como "o conjunto dos documentos tidos em conta para serem submetidos aos procedimentos analíticos" seria composto pelos trabalhos apresentados no Quadro 1, dos quais apresentamos, por meio do Quadro 2, uma breve caracterização em termos de objeto matemático em foco, objetivo, fundamentação teórica, aspectos metodológicos e sujeitos de pesquisa (se houver). 


\begin{tabular}{|c|c|c|c|c|c|}
\hline Autores/Data & $\begin{array}{c}\text { Objeto } \\
\text { Matemático }\end{array}$ & Objetivo & $\begin{array}{c}\text { Fundamentação } \\
\text { Teórica }\end{array}$ & $\begin{array}{c}\text { Aspectos } \\
\text { Metodológicos } \\
\end{array}$ & Sujeitos \\
\hline Savioli (2006) & $\begin{array}{l}\text { Equações } \\
\text { Algébricas }\end{array}$ & $\begin{array}{l}\text { Fazer com que } \\
\text { os estudantes } \\
\text { tenham um } \\
\text { momento de } \\
\text { reflexão sobre } \\
\text { as equações } \\
\text { algébricas, } \\
\text { momento este } \\
\text { nem sempre } \\
\text { oportunizado } \\
\text { no curso de } \\
\text { licenciatura em } \\
\text { Matemática. }\end{array}$ & $\begin{array}{lr}\text { Não há uma } \\
\text { fundamentação } \\
\text { teórica explícita. } \\
\text { Recorre-se } r \\
\text { ideia à } \\
\text { utilização } & \text { de } \\
\text { História } & \text { da } \\
\text { Matemática } & \text { no } \\
\text { Ensino. } & \end{array}$ & $\begin{array}{l}\text { A Resolução de } \\
\text { Problemas foi adotada } \\
\text { como metodologia. }\end{array}$ & $\begin{array}{l}\text { Estudantes de } \\
\text { um curso de } \\
\text { Licenciatura } \\
\text { em } \\
\text { Matemática } \\
\text { (na realidade } \\
\text { trata-se de } \\
\text { uma proposta } \\
\text { para ser } \\
\text { implementada } \\
\text { com alunos } \\
\text { desse curso, } \\
\text { mas não da } \\
\text { análise da } \\
\text { aplicação do } \\
\text { que está } \\
\text { sendo proposto). } \\
\text { pron }\end{array}$ \\
\hline Savioli (2009) & $\begin{array}{l}\text { Não há um } \\
\text { objeto } \\
\text { específico }\end{array}$ & 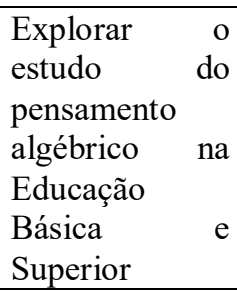 & $\begin{array}{l}\text { Concepções } \\
\text { sobre Álgebra } \\
\text { nas óticas de } \\
\text { diferentes } \\
\text { autores. }\end{array}$ & $\begin{array}{l}\text { É uma pesquisa } \\
\text { bibliográfica. }\end{array}$ & Não há \\
\hline $\begin{array}{l}\text { Mondini e } \\
\text { Bicudo } \\
(2010)\end{array}$ & $\begin{array}{l}\text { Não há um } \\
\text { objeto } \\
\text { específico }\end{array}$ & $\begin{array}{lr}\text { Estudar } & \text { as } \\
\text { concepções que } & \\
\text { professores } & \text { de } \\
\text { Álgebra } & \text { de } \\
\text { cursos } & \text { de } \\
\text { licenciatura } & \\
\text { têm sobre a } & \text { relevância } \\
\text { dessa disciplina } & \\
\text { na formação de } \\
\text { professores de } \\
\text { Matemática. }\end{array}$ & $\begin{array}{l}\text { Concepções } \\
\text { sobre Álgebra } \\
\text { nas óticas de } \\
\text { diferentes } \\
\text { autores. }\end{array}$ & $\begin{array}{l}\text { Pesquisa qualitativa } \\
\text { desenvolvida } \\
\text { fenomenologicamente, } \\
\text { recorrendo-se } \\
\text { Entre-vistas } \\
\text { (encontros presenciais } \\
\text { por meio dos quais a } \\
\text { pesquisadora olhava e } \\
\text { ouvia a fala do/a } \\
\text { depoente). }\end{array}$ & $\begin{array}{l}\text { Professores } \\
\text { de Álgebra de } \\
\text { um curso de } \\
\text { Licenciatura } \\
\text { em } \\
\text { Matemática. }\end{array}$ \\
\hline $\begin{array}{l}\text { Elias, } \\
\text { Barbosa e } \\
\text { Savioli (2012) }\end{array}$ & Grupo & $\begin{array}{l}\text { Verificar como } \\
\text { estudantes de } \\
\text { licenciatura em } \\
\text { Matemática } \\
\text { lidam com } \\
\text { conceitos de } \\
\text { Matemática } \\
\text { Avançada que } \\
\text { têm um novo } \\
\text { estatuto } \\
\text { cognitivo como } \\
\text { conceitos } \\
\text { construídos a } \\
\text { partir } \\
\text { definições de } \\
\text { formais, a } \\
\text { saber, conceitos } \\
\text { que envolvem o } \\
\text { estudo } \\
\text { objeto do } \\
\text { matemático }\end{array}$ & $\begin{array}{l}\text { Pensamento } \\
\text { Matemático } \\
\text { Avançado. }\end{array}$ & $\begin{array}{l}\text { Os dados foram } \\
\text { colocados por meio de } \\
\text { entrevistas } \\
\text { semiestruturadas. }\end{array}$ & $\begin{array}{l}\text { Dois } \\
\text { estudantes de } \\
\text { um curso de } \\
\text { Licenciatura } \\
\text { em } \\
\text { Matemática. }\end{array}$ \\
\hline
\end{tabular}




\begin{tabular}{|c|c|c|c|c|c|}
\hline & & rupo. & & & \\
\hline $\begin{array}{l}\text { Kirnev e } \\
\text { Savioli (2017) }\end{array}$ & $\begin{array}{l}\text { Anéis de } \\
\text { Polinômios }\end{array}$ & $\begin{array}{l}\text { Investigar que } \\
\text { set-befores e } \\
\text { met-befores } \\
\text { estão } \\
\text { envolvidos em } \\
\text { resoluções de } \\
\text { atividades } \\
\text { sobre anéis de } \\
\text { polinômios. }\end{array}$ & $\begin{array}{l}\text { Ideias acerca do } \\
\text { Pensamento } \\
\text { Matemático } \\
\text { Avançado e de } \\
\text { Pirâmide de } \\
\text { Avaliação. }\end{array}$ & $\begin{array}{l}\text { A aplicação das } \\
\text { atividades } \\
\text { desenvolvidas a partir } \\
\text { das referências } \\
\text { bibliográficas da } \\
\text { disciplina Estruturas } \\
\text { Algébricas envolveu } \\
\text { uma avaliação } \\
\text { diagnóstica } \\
\text { posteriormente, a } \\
\text { reaplicação dessas } \\
\text { atividades a } \\
\text { disponibilizando aos } \\
\text { estudantes materiais } \\
\text { complementares. }\end{array}$ & $\begin{array}{l}\text { Sete } \\
\text { estudantes de } \\
\text { um curso de } \\
\text { Bacharelado } \\
\text { em } \\
\text { Matemática } \\
\text { que já haviam } \\
\text { cursado a } \\
\text { disciplina } \\
\text { Estruturas } \\
\text { Algébricas. }\end{array}$ \\
\hline
\end{tabular}

Quadro 2 - Breve caracterização das pesquisas que fazem parte do corpus de análise Fonte: dados da pesquisa

Constituído o corpus de análise, realizamos a leitura flutuante, que, conforme Bardin (2004, p. 90), "consiste em estabelecer contato com os documentos a analisar e em conhecer o texto deixando-se invadir por impressões e orientações". Não estabelecemos a priori nenhuma hipótese, mas tivemos como foco salientar aspectos essenciais nas investigações sobre Álgebra produzidas por membros do GT04. Da leitura flutuante evidenciaram-se índices que, segundo Bardin (2004, p. 94), podem ser referências explícitas a certas temáticas, que nos conduziram em "operações de recorte do texto em unidades comparáveis de categorização para análise temática". Os cinco artigos foram lidos e relidos, separadamente, por cada um de nós e, ao longo dessa leitura, destacamos aspectos relacionados ao ensino e à aprendizagem de Álgebra e também à concepção de Álgebra adotada pelos autores. Cada um de nós, ainda separadamente, procurou criar categorias de análise a partir dos pontos destacados. Após essa etapa, confrontamos as análises que havíamos feito individualmente e chegamos a um conjunto final de categorias a serem analisadas, que são as seguintes:

$$
\begin{aligned}
& \text { C1 - O que é Álgebra? } \\
& \text { C2 - O papel da Álgebra } \\
& \text { C3 - Requisitos para aprender Álgebra } \\
& \text { C4 - Como a Álgebra é ensinada e como deveria ser ensinada } \\
& \text { C5 - Natureza das dificuldades evidenciadas na aprendizagem de Álgebra }
\end{aligned}
$$

No âmbito de cada uma das categorias, realizamos uma análise interpretativa, na concepção de Severino (2007), dos extratos selecionados. Nesta, buscamos superar as ideias expressas no texto, indo além delas, lendo nas entrelinhas e cotejando-as com reflexões realizadas por outros investigadores da temática em foco. Neste artigo, nos limitamos às categorias $\mathrm{C} 1$ e C2. Nas próximas seções, discorremos sobre cada uma delas, exemplificando- 
as com extratos dos textos analisados, e estabelecemos relações com reflexões realizadas por outros autores de renome no domínio da Educação Algébrica.

\title{
3 C1 - O que é Álgebra?
}

Em relação a essa categoria, é necessário ressaltar a dificuldade de chegarmos a um consenso a respeito do que é Álgebra. O que buscamos é, a partir das considerações trazidas pelos autores das produções do GT04 analisadas, identificar aspectos por eles tidos como integrantes da essência da Álgebra para, posteriormente, agregar ideias de outros autores da Educação Matemática acerca da temática em foco nessa categoria.

Savioli (2009), tendo por meta caracterizar a Álgebra, recorre a aspectos históricos. Afirma que:

\begin{abstract}
A literatura referente à história da Matemática apresenta que, desde a Babilônia até meados da renascença, a Álgebra era um modo sofisticado de resolver problemas aritméticos, consistindo basicamente em resolver equações. [...] A partir do século XVIII, a Álgebra passou a incorporar, além da resolução de equações, pela influência principalmente de matemáticos como Abel e Galois, as chamadas estruturas algébricas, como grupos, anéis, corpos, espaços vetoriais, e outros (SAVIOLI, 2009, p. 2-3).
\end{abstract}

Os sujeitos da investigação de Mondini e Bicudo (2010), professores de disciplinas de Álgebra em cursos de Licenciatura em Matemática, ao buscarem caracterizar a Álgebra trazem, em seus discursos, aspectos relacionados a essas considerações apresentadas por Savioli (2009). Um deles afirma que as equações, e especialmente as equações algébricas, são a essência da Álgebra, uma vez que estiveram na gênese dessa área da Matemática. Outros fazem referências às estruturas, como corpos, anéis, grupos e espaços vetoriais, como elementos centrais da Álgebra.

Essas questões históricas trazidas por Savioli (2009) estão, de certa forma, relacionadas também às diferentes leituras de Álgebra elencadas por Fiorentini, Miorin e Miguel (1993) e retomadas pela autora em seu texto. São elas:

\footnotetext{
Uma primeira que encara a Álgebra não só como o estudo de equações, mas como o de operações definidas sobre entes abstratos e que se divide em tradicional e moderna; uma segunda que tem como base a contribuição de várias culturas à formação dessa área de conhecimento e que fala em Álgebra babilônica, álgebra egípcia, entre outras; uma terceira que baseia-se nos estágios para o desenvolvimento da Álgebra, mais especificamente, da notação algébrica; uma quarta que se assegura na significação que é dada aos símbolos da linguagem algébrica; uma quinta que tem como critério os métodos de abordagem da resolução de equações e que distingue três períodos no desenvolvimento da Álgebra: o intra-operacional (sic) que buscava um método particular para cada problema, o inter-operacional (sic) que buscava fórmulas de resolução de equações gerais de diversos graus e o trans-operacional (sic) que utilizava o cálculo infinitesimal para resolução de equações algébricas (SAVIOLI, 2009, p. 13).
} 
Ainda aprofundando suas reflexões baseadas em questões históricas, Savioli (2009) recorre às considerações de Lins e Gimenez (1997) que, a partir dos trabalhos de matemáticos como al-Khwarizmi e Dieudonné, afirmam existir duas linhas de caracterização da atividade algébrica: a primeira, pelo uso de notações, e a segunda, pela presença de certos conteúdos, como, por exemplo, cálculo literal, equações, funções etc.

Os professores entrevistados por Mondini e Bicudo (2010, p. 47) parecem, em alguma medida, ratificar essa ideia. Ao afirmarem, por exemplo, que a Álgebra é "o que está presente em praticamente todo o tipo de conhecimento matemático" ou que "a Álgebra é a parte sintética da Matemática", a nosso ver, é provável que esses sujeitos estejam, em alguma medida, fazendo referência às notações e às expressões algébricas. Essa nossa percepção é reforçada pela afirmação de que Álgebra "é lógica, aritmética, teoria dos conjuntos, estruturas algébricas e espaços vetoriais". Ou seja, para esses professores, parece que a Álgebra é aquilo que há de comum entre esses diferentes conhecimentos, os conteúdos - e as notações - que, de alguma maneira, estão diretamente relacionados a todos eles.

Os depoimentos desses sujeitos entrevistados por Mondini e Bicudo (2010), dos quais já apresentamos alguns trechos nas análises dessa categoria, trazem, em seu bojo, indícios das diferentes concepções de Álgebra, segundo Fiorentini, Miorin e Miguel (1993), apresentadas por Savioli:

[ ] a processológica, que encara a Álgebra como um conjunto de procedimentos; a lingüístico-estilística que aborda a Ảlgebra como uma linguagem específica; a lingüístico-sintático-semântica que concebe a Álgebra como uma linguagem, contudo em sua dimensão sintático-semântica; e a lingüístico-postulacional, que, de acordo com Piaget e Garcia (1987, p. 163) 'encara a Álgebra como a ciência das estruturas gerais comuns a todas as partes da Matemática, incluindo a lógica' (SAVIOLI, 2009, p. 13).

Usiskin (1995) também apresenta quatro diferentes concepções para a Álgebra, que são retomadas por Savioli (2009): Aritmética generalizada; estudo de procedimentos para solucionar determinados tipos de problemas; estudo de relações entre grandezas; e estudo das estruturas. Ao tecermos nossos comentários acerca da categoria $\mathrm{C} 2$, estabelecemos um diálogo mais estreito entre essas ideias de Usiskin (1995) e as produções do GT04 analisadas neste artigo, mas, neste momento, o que entendemos como relevante a ser destacado é que uma dessas concepções, Álgebra como Aritmética generalizada, foi revelada pelos entrevistados de Mondini e Bicudo (2010). E, a esse respeito, salientamos que a maneira como a Aritmética e a Álgebra se relacionam não é unanimidade entre os educadores matemáticos. Há aqueles que consideram a Álgebra como a generalização da Aritmética e, portanto, a existência de uma passagem da Aritmética para a Álgebra e outros que concebem a Aritmética como parte 
integrante da Álgebra.

Lins e Gimenez (1997), citados por Savioli (2009, p. 10), trazem um outro aspecto relacionado à essência da Álgebra que a considera "como um caminho de pensamento, um caminho de interpretação e compreensão de situações do dia-a-dia". Ainda no artigo de Savioli (2009, p. 9), é apresentada a ideia de Pimm (1995) que "relaciona a Álgebra com transformações. Acredita que a Álgebra seja um pouco de forma e um pouco de transformação".

Convém observar que, a ideia de tentar responder à questão o que é Álgebra? a partir de um viés histórico é recorrente na Educação Matemática, o que pode ser constatado em Savioli (2009), que embasa suas considerações a partir do que apresentam Fiorentini, Miorin e Miguel (1993) e Lins e Gimenez (1997), e em como os professores de Álgebra sujeitos do estudo de Mondini e Bicudo (2010) responderam nas entrevistas que concederam.

A esse respeito, Kluth (2004, p. 3) ressalta que, embora matemáticos e professores de Matemática tenham uma compreensão acerca da Álgebra e possam caracterizá-la adotando como referência os conteúdos estudados em seus cursos de graduação, recorrer a outras áreas de conhecimento que, de alguma forma, estão relacionadas a ela, como é o caso, por exemplo, da História da Matemática, é fundamental quando "se quer ir além deste terreno delineado pelos currículos universitários e escolares, no sentido de enriquecer a compreensão do que é Álgebra. [...] A História da Matemática pode ser um terreno bastante propício para a busca dos elementos constitutivos e constituintes da Álgebra".

Para Freudenthal (1977), no cotidiano escolar, a Álgebra costuma ser associada à resolução de equações e, segundo ele, o porquê de tal associação é histórico: embora não possa ser dito, em razão especialmente de questões ligadas ao simbolismo, que os babilônios faziam Álgebra na acepção moderna do termo, o trabalho por eles desenvolvido relacionado à resolução de equações, como também ressalta Savioli (2009), trouxe em seu bojo elementos presentes no que hoje chamamos de Álgebra, que, para Freudenthal (1977) está atrelada à habilidade em descrever relações, aos procedimentos e às técnicas de resolver problemas a partir de tais relações.

Adotando uma visão fenomenológica da História, Kluth (2004, p. 5) afirma que as características da Álgebra "são invariantes, componentes da síntese contínua que revela o movimento da construção humana do conhecimento algébrico numa perspectiva atemporal que contempla passado, presente e futuro, ainda que como possibilidade, das realizações humanas". Destaca, então, que a questão o que é Álgebra? pode ser respondida a partir dos aspectos estruturais da Álgebra em termos de alguns invariantes, estando estes organizados nas seguintes categorias: Formas Cognitivas, Formas dos Objetos Matemáticos, Formas de Expressão e 
Formas de Organização.

As Formas Cognitivas são constituídas pelos invariantes: pensar, abstrair, imaginar; as Formas dos Objetos Matemáticos são constituídas pelos invariantes: quanto a natureza - números, razão, proporção, equação, função, estrutura, grupos, ideais, matrizes, determinantes, vetor, relação, polinômios - quanto ao modo de ser qualidade, quantidade, magnitude, contínuo, discreto e relação - quanto ao modo da construção do conhecimento - continuidade, análise, síntese e resgate; as Formas de Expressão são constituídas pelos invariantes: retórica, sincopada, simbólica e as Formas de Organização são constituídas pelos invariantes: conceitos, abstração, ampliação de conceitos, generalização, estruturas, estabelecimento de relações, comprovações, método e postulação (KLUTH, 2004, p. 5-6).

Sintetizando suas análises, a autora afirma que, como uma articulação dos invariantes, a Álgebra "explicita o modo com que abordamos e lidamos com os objetos matemáticos, porém mais do que isto, ao explicitar ela pode recuperar e estender conceitos de objetos matemáticos constituídos ou em construção" (KLUTH, 2004, p. 6).

Sfard (1995), também recorrendo a exemplos históricos, destaca que pode ser observada uma unanimidade relacionada às origens da Álgebra: as ideias relativas a esse campo da Matemática se desenvolveram, sempre, a partir de tentativas de tratar de uma maneira geral os processos de cálculo. Nesse sentido, para a autora, a generalidade é uma das características que diferenciam a Álgebra da Aritmética. É interessante observar que essa relação entre Aritmética e Álgebra e o fato de a segunda prever uma generalidade que não é característica da primeira está presente, como evidencia Jones (1993, p. 27, tradução nossa), até mesmo na definição apresentada em alguns dicionários, como é o caso do Chambers, segundo o qual a Álgebra "é um método de cálculo por símbolos - por meio de letras empregadas para representar quantidades e sinais para representar suas relações - formando assim um tipo de aritmética generalizada".

Para Sfard (1995, p. 18, tradução nossa), embora a resposta para a questão o que é Álgebra? não seja única, parece haver uma concordância entre diferentes autores em relação à Álgebra ser "uma ciência dos cálculos generalizados". Jones (1993, p. 27, tradução e grifo nossos), de certa forma, ratifica essa ideia, destacando que a "generalização é o coração da Álgebra". Há para o autor outros dois elementos essenciais à Álgebra: a busca por padrões, passo essencial rumo ao estabelecimento de generalizações, e a introdução de alguma forma de simbolização para indicar uma quantidade desconhecida.

Convém salientar o destaque dado por Sfard (1995) ao fato de que, enquanto a importância da generalização parece ser ponto pacífico em diferentes tentativas de definir o que é Álgebra, as discordâncias estão nas opiniões distintas dos autores acerca dos meios necessários para a implementação de métodos algébricos. Para alguns, como Garcia e Piaget (1989) e Unguru (1975), a notação simbólica é claramente parte integrante do ramo da 
Matemática que hoje denomina-se Álgebra, uma vez que o simbolismo operacional é uma das principais características do modo de pensar algébrico.

Para outros, no entanto, a linguagem algébrica e os símbolos intrínsecos a ela "não são o único veículo possível de generalidade" (SFARD, 1995, p. 18). A partir dessas ideias, afirma que, em sua concepção, o termo Álgebra deve ser empregado para fazer referência "a qualquer tipo de empreendimento matemático relacionado a processos computacionais generalizados, quaisquer que sejam as ferramentas usadas para transmitir essa generalidade" (SFARD, 1995, p. 18).

Uma vez que, por meio das considerações apresentadas na categoria $\mathrm{C} 1$, não temos a pretensão de explicitar uma resposta cabal para a questão o que é Álgebra?, mas, sim, destacar as reflexões relacionadas a ela emergentes das produções do GT04 e do estabelecimento de diálogos entre as ideias presentes nestes textos e aquelas provenientes de algumas investigações desenvolvidas por outros autores da Educação Matemática, encerramos nossa análise salientando mais uma possível resposta para a questão em foco, recuperada por Jones (1993, p. 27, tradução nossa) da enciclopédia Children's Brittanica e que, em certa medida evidencia a importância da Álgebra, por permear significativamente outros domínios matemáticos: “Álgebra é o mais básico ramo da Matemática porque está relacionado com aquilo que é verdadeiro em todos os outros ramos" dessa ciência.

\section{C2 - O papel da Álgebra}

Em relação, ao papel da Álgebra, a análise dos textos nos evidenciou cinco principais vieses, explicitamente presentes nas produções do GT04 relacionadas ao tema. São eles:

I. A compreensão dos aspectos estruturais, abstratos, formais e lógicos-axiomáticos da Matemática.

II. A generalização de conceitos da Aritmética.

III. A comunicação em Matemática.

IV. O desenvolvimento de caminhos de pensamento, interpretação e compreensão de situações do dia-a-dia.

V. A organização e a fundamentação de conceitos na formação do futuro professor de Matemática.

No que diz respeito ao papel identificado por (I), tratando especialmente da formação do professor de Matemática, Mondini e Bicudo (2010, p. 50) justificam a necessidade de o "docente conhecer as estruturas algébricas para um aprofundamento teórico sobre o campo de 
conhecimento da Matemática, um dos conteúdos de seu objeto de trabalho". A partir das ideias de Souza (2008), Mondini e Bicudo (2010, p. 53) afirmam que, sem as disciplinas de Álgebra, os licenciandos sairiam do curso sem o alicerce básico para ensinar os princípios fundamentais da Matemática. Acrescentam ainda que, "embora haja distanciamento entre o que os alunos estudam na Licenciatura e o que julgam importante trabalhar na educação básica, o conhecimento das estruturas é importante para a compreensão do que está subjacente à sua aprendizagem formal".

Ainda relacionado à (I), Elias, Barbosa e Savioli (2012, p. 3) apontam que é também nas disciplinas de Álgebra que os estudantes têm contato com demonstrações, “com símbolos diversos, com um alto grau de abstração e de formalismo". Exigem, portanto, dos estudantes "uma nova maneira de encarar a Matemática, entendendo-a como um sistema lógico-dedutivo". Os autores reforçam que:

[ ] as disciplinas Análise, Álgebra e Geometria Euclidiana são responsáveis por introduzirem o estudante iniciante ao método lógico-axiomático, permitindo que ele compreenda aspectos estruturais da matemática e sua forma de criação, iniciando, desta forma, [...] a transição do Pensamento Matemático Elementar (PME) para o Pensamento Matemático Avançado (PMA) (ELIAS; BARBOSA; SAVIOLI, 2012, p. 7).

O papel (II) é destacado por Mondini e Bicudo (2010, p. 48), tendo em vista especialmente os cursos de formação inicial de professores de Matemática. As autoras, nesse contexto, ressaltam que a importância de tal generalização está relacionada ao fato de a Aritmética abranger "boa parte dos conteúdos de Matemática trabalhados no Ensino Fundamental", um dos lócus de atuação do licenciado.

Em relação à (III), Mondini e Bicudo (2010, p. 48) apontam que, na formação inicial de docentes, "ao ensinar Álgebra, o professor ensina ao estudante uma nova linguagem e uma possibilidade diferenciada de organização" das ideias da Matemática. Savioli (2009), por sua vez, ressalta que:

O conhecimento dos símbolos e da linguagem matemática é imprescindível para a formação de um professor de Matemática e de um matemático. É com eles que o estudante conseguirá se comunicar matematicamente e se expressar para o leitor, isto é, escrever numa linguagem clara que todos possam compreender (SAVIOLI, 2009, p. 9).

Segundo a mesma autora, "é na Álgebra que ele começa a conhecer o que é Matemática e como expressar-se nela, entendendo e podendo comunicar-se com o mundo matemático" (SAVIOLI, 2009, p. 7).

Relacionado a esse papel da Álgebra para comunicação em Matemática entra em jogo o papel de linguagem assumido pela Álgebra. Visando compreender, do ponto de vista histórico, 
a gênese dessa ideia, Savioli (2009) recorre às considerações de Radford (2001), que afirma que:

\begin{abstract}
As evidências históricas da existência do pensamento algébrico nas civilizações antigas podem ser vistas em papiros egípcios e babilônios em que as soluções sugerem um caminho explícito e sistemático de tratar com a primeira linguagem algébrica literal. Nestes papiros, a linguagem algébrica pode ser vista como uma ferramenta heurística, isto é, um cálculo com expressões simbólicas. Já na idade média ou renascentista, a linguagem algébrica começa a aparecer como um objeto autônomo levando a uma nova organização teórica, isto é, de um cálculo sobre expressões simbólicas (SAVIOLI, 2009, p. 4-5).
\end{abstract}

A partir dessa análise histórica, a autora ratifica as ideias de Radford (2001) para quem "a linguagem algébrica emergiu como uma ferramenta ou técnica e mais tarde evoluiu sócio culturalmente passando a ser considerada como objeto matemático" (SAVIOLI, 2009, p. 5).

O desenvolvimento da linguagem algébrica se deu, conforme afirma Savioli (2009, p. 12), com base nas ideias de Malisani (1999), "a partir do progresso dos métodos e estratégias historicamente utilizados para resolver equações".

Os professores entrevistados por Mondini e Bicudo (2010, p. 48), ao definirem a Álgebra como linguagem, "referem-se a ela como um meio de escrever, compreender e comunicar as ideias da Matemática, e não simplesmente como uma maneira de traduzir ideias da língua materna para a linguagem da Matemática ou da Matemática para a língua materna”. A esse respeito, Savioli $(2009$, p. 7) destaca que é na Álgebra que o estudante "começa a conhecer o que é matemática e como expressar-se nela, entendendo e podendo comunicar-se com o mundo matemático".

Ainda, a autora traz em seu texto considerações de Fiorentini, Miorin e Miguel (1993, p. 85) a respeito de uma possível subordinação do pensamento algébrico à linguagem, o que, para os autores, não é adequada, uma vez que "desconsidera o fato de que, tanto no plano histórico quanto no pedagógico, a linguagem é, pelo menos a princípio, a expressão de um pensamento" e que, por esta razão, entre linguagem e pensamento algébrico deve haver não uma subordinação, mas uma relação dialética.

Em relação ao papel IV da Álgebra, Savioli $(2009$, p, 8) afirma que “a Álgebra é essencial porque ela é um caminho de pensamento, um caminho de interpretação e compreensão de situações do dia a dia". Tendo por base as ideias de Moses (2000), a autora salienta que "o pensamento algébrico é o veículo para exploração do mundo e suas regularidades" (SAVIOLI, 2009, p. 8).

Finalmente, a respeito do papel que identificamos por (V), Modindi e Bicudo (2010, p. 50) afirmam que, na Licenciatura, a Álgebra pode ser vista como uma oportunidade de o estudante "construir um conhecimento organizado e fundamentado para que, ao atuar como 
professor da Educação Básica, trabalhe com atividades que criem um ambiente de aprendizagem real aos seus alunos".

Os dados apresentados na categoria C2 evidenciam que, a partir das investigações de autoria de membros do GT04, pode-se depreender que a Álgebra desempenha papéis tanto para a construção do conhecimento matemático do estudante, quanto para a formação do professor que irá mediar esse processo de construção em sala de aula. Tais papéis, de maneira sintética, estão vinculados ao conhecimento das estruturas, das demonstrações, do simbolismo e do formalismo inerentes à área, à centralidade das generalizações em Matemática e à apropriação da linguagem e do pensamento algébrico para o sujeito pensar e se comunicar matematicamente.

Em relação aos papéis da Álgebra, se ampliarmos nosso olhar para as produções de outros autores no domínio da Educação Algébrica, podemos identificar uma série de visões a esse respeito. Destacamos aqui, com base na tese de doutorado de Figueiredo (2007) que produziu uma síntese sobre o tema, as ideias de Zalman Usiskin (1995) e as de Leslie Lee (2001) que, em alguma medida, contemplam aspectos presentes nas pesquisas desenvolvidas no âmbito do GT04 e outros não identificados nesses trabalhos.

Usiskin (1995) descreve o que denomina de quatro concepções de Álgebra, mas que, a nosso ver, estão diretamente relacionadas aos diferentes papéis da Álgebra. São elas:

U1. Álgebra como Aritmética generalizada;

U2. Álgebra como estudo de procedimentos para resolver certos tipos de problemas;

U3. Álgebra como estudo de relações entre grandezas;

U4. Álgebra como estudo das estruturas.

Por sua vez, Lee (2001) estabelece as seguintes categorias de concepções de Álgebra e de Educação Algébrica:

L1. Álgebra como linguagem

L2. Álgebra como caminho de pensamento

L3. Álgebra como atividade

L4. Álgebra como ferramenta

L5. Álgebra como Aritmética generalizada

L6. Álgebra como cultura

Em relação a essas concepções estabelecidas por Lee (2001), L1, L2 e L5 têm títulos que são autoexplicativos. Deter-nos-emos a alguns esclarecimentos acerca de L3, L4 e L6.

Em relação à Álgebra como atividade (L3), Lee (2001) indica que esta concepção está relacionada à existência de uma ampla gama de atividades em diferentes áreas, mobilizando 
ideias da Álgebra, em especial a manipulação simbólica (simplificar expressões, resolver equações etc.) e a modelagem matemática. A autora considera que a resolução de problemas é o tipo de atividade que possibilita a coordenação de aspectos de manipulação simbólica e de modelagem.

Pelo fato de Lee (2001) considerar a Álgebra como uma atividade de resolução de problemas, necessariamente ferramentas semióticas dessa área da Matemática são empregadas na resolução. A concepção de Álgebra como ferramenta (L4) está diretamente relacionada a esse aspecto. A Álgebra é uma ferramenta que possibilita tornar mais eficiente o pensamento, expressar e transformar ideias e assim resolver problemas, não somente da Matemática e das ciências em geral, mas também do mundo real, que, sem recorrer a ela, seriam impossíveis de serem solucionados.

A respeito da concepção Álgebra como cultura (L5), Figueiredo (2007) a sintetiza, afirmando que:

\begin{abstract}
Tal concepção permite reunir as anteriores e tecê-las numa rica teia do que a Álgebra elementar seria. Nela, atividades algébricas requerem o uso de ferramentas algébricas, fomentando o pensamento algébrico e a linguagem de comunicação algébrica. Não está isolada do resto da cultura elementar em Matemática, mas entremeia-se no currículo com Aritmética e Geometria, como tem ocorrido historicamente. [...] a Álgebra tem o potencial de tornar-se o tema unificador para a Matemática elementar: Aritmética como Álgebra dos números, Geometria como Álgebra das formas e Estatística como Álgebra das medidas. A sugestão da autora é que a Matemática elementar envolva uma imersão na cultura algébrica (FIGUEIREDO, 2007, p. 65-66).
\end{abstract}

Nos trabalhos produzidos sobre Álgebra pelo GT04, notamos convergência entre o primeiro papel (I) da Álgebra que deles emergiu, a saber, a compreensão dos aspectos estruturais, abstratos, formais e lógicos-axiomáticos da Matemática, e a concepção U4 de Usiskin (1995). Da mesma forma, o segundo papel (II) decorrente das produções neste artigo analisadas, a generalização de conceitos da Aritmética, dialoga tanto com a concepção U1 de Usiskin (1995) quanto com a L5 de Lee (2001).

O terceiro papel da Álgebra (III), a comunicação em Matemática, relaciona-se à L1, enquanto o quarto papel (IV), o desenvolvimento de caminhos de pensamento, interpretação e compreensão de situações do dia-a-dia, tem correspondência com L2. O quinto papel (V), a organização e a fundamentação de conceitos na formação do futuro professor de Matemática, relacionado diretamente à formação do docente, não está vinculado, ao menos de maneira explícita, a nenhuma das concepções de Usiskin (1995) e de Lee (2001).

Notamos que as concepções U2 e U3 de Usiskin (1995) e L3 e L4 de Lee (2001) não foram contempladas nas discussões acerca do papel da Álgebra presentes nos artigos produzidos pelos integrantes do GT04 (Quadro 3). 


\begin{tabular}{|c|c|c|}
\hline \multirow{2}{*}{$\begin{array}{c}\text { Papéis da Álgebra } \\
\text { (GT04) }\end{array}$} & \multicolumn{2}{|c|}{ Concepções de Álgebra } \\
\cline { 2 - 3 } & Usiskin (1995) & Lee (2001) \\
\hline I & U4 & ---- \\
\hline II & U1 & L5 \\
\hline III & ---- & L1 \\
\hline IV & ---- & L2 \\
\hline V & ---- & ---- \\
\hline
\end{tabular}

Quadro 3 - Relações entre os papéis da Álgebra e as concepções de Álgebra de Usiskin e de Lee Fonte: dados da pesquisa

Os dados apresentados no Quadro 3 sintetizam as relações por nós detectadas entre os diferentes papéis da Álgebra presentes nas investigações sobre o tema produzidas pelos membros do GT04 e as concepções de Álgebra estabelecidas por Usiskin (1995) e Lee (2001) que, como já mencionamos, foram selecionadas dentre aquelas existentes no campo da Educação Algébrica por estarem mais próximas das reflexões presentes nos textos por nós analisados neste artigo.

\section{Considerações finais}

Neste artigo, tivemos como objetivo refletir, a partir da análise de cinco produções do Grupo de Trabalho Educação Matemática no Ensino Superior (GT04) da Sociedade Brasileira de Educação Matemática, acerca de questões relacionados ao ensino e à aprendizagem de Álgebra. Atemo-nos, neste trabalho, a dois aspectos: às tentativas de respostas à questão $o$ que é Álgebra? e às considerações a respeito dos papeis da Álgebra.

As ponderações feitas pelos autores do GT serviram de ponto de partida para aprofundamentos acerca do que estava sendo discutido, estabelecendo-se um diálogo entre as produções analisadas (explicitadas por meio do Quadro 1) e reflexões presentes em outras investigações conduzidas por pesquisadores de renome no campo da Educação Algébrica.

Por meio do estudo realizado, como indica o título deste artigo, pudemos refletir acerca de algumas ideias. Em primeiro lugar, evidenciou-se o quão difícil é a tarefa de dizer o que é Álgebra. Percebemos que não há um consenso a esse respeito, mas que, ao pensar acerca dessa indagação, além de entrarem em jogo as concepções de Álgebra daqueles que buscam respondêla e como estes relacionam este campo da Matemática com a Aritmética, é recorrente: adotarse um viés histórico, buscar definir a Álgebra a partir dos conteúdos matemáticos que normalmente são estudados em disciplinas relacionadas a essa temática, caracterizar a Álgebra a partir de seus aspectos estruturais e dos invariantes observados em tais aspectos e, ainda, compreender a Álgebra como aquilo que há de comum em todas as diferentes áreas da 
Matemática. As tentativas de respostas, por parte de distintos pesquisadores, à supracitada questão também iluminam a centralidade ocupada, na Álgebra, pela ideia de generalização e as divergências de opiniões a respeito do papel da notação simbólica para a implementação de métodos algébricos.

Em segundo lugar, no que concerne aos papeis da Álgebra, das produções dos pesquisadores do GT04, emergem cinco: (i) a compreensão dos aspectos estruturais, abstratos, formais e lógicos-axiomáticos da Matemática; (ii) a generalização de conceitos da Aritmética; (iii) a comunicação em Matemática; (iv) o desenvolvimento de caminhos de pensamento, interpretação e compreensão de situações do dia-a-dia; e (v) a organização e a fundamentação de conceitos na formação do futuro professor de Matemática. Nota-se, portanto, que há papeis tanto relacionados à construção do conhecimento matemático do estudante, quanto para a formação do professor que irá mediar tal construção em sala de aula (observando-se que, mesmo os papeis de (i), (ii), (iii) e (iv), que não fazem referência à formação do professor, devem ser considerados nas abordagens propostas para a Álgebra nas licenciaturas e formações continuadas).

Quatro desses papeis da Álgebra, identificados nas produções dos integrantes do GT04, dialogam, em alguma medida, como evidenciam os dados presentes no Quadro 3, com as diferentes concepções de Álgebra enunciadas por autores como Usiskin (1995) e Lee (2001) e que foram sintetizadas por Figueiredo (2007). Apenas o quinto papel, por ser muito específico à formação de professores, não está explicitamente vinculado à nenhuma dessas concepções.

Em nossa concepção, em termos dos avanços alcançados por intermédio desta pesquisa, os resultados apresentados neste artigo permitem uma apurada identificação em relação aos elementos que caracterizam a Álgebra e aos diferentes papéis por ela assumidos. Entendemos que ter clareza acerca desses pontos é algo essencial para professores, estudantes da licenciatura em Matemática e de pós-graduação e pesquisadores da área, uma vez que tais ideias são alicerces para outras reflexões no campo da Educação Algébrica.

Como mencionamos nas seções 1 e 2, as análises dos trabalhos sobre Álgebra produzidos pelos integrantes do GT04 desde a criação desse Grupo nos permitiram refletir também acerca de outros três aspectos, além desses dois tratados neste artigo. São eles: (i) os requisitos para aprender Álgebra; (ii) como a Álgebra é ensinada e como deveria ser ensinada e (iii) as naturezas das dificuldades evidenciadas na aprendizagem de Álgebra. Apresentar as discussões a respeito dessas temáticas, a partir das cinco produções que compõem o corpus de nossa pesquisa, configura os objetos de nossas investigações futuras.

Um último ponto a ser destacado, e que indica caminhos profícuos para novos estudos, 
é o número relativamente pequeno de trabalhos sobre a temática desenvolvidos no âmbito do GT04, considerando a sua já extensa trajetória, o que é surpreendente dado à importância da Educação Algébrica para a Educação Matemática.

\section{Referências}

BARDIN, L. Análise de Conteúdo. $3^{\text {a }}$ ed. Lisboa: Edições 70, 2004.

BIANCHINI, B. L.; LIMA, G. L., GOMES, E. Cálculo, Análise e Álgebra Linear: indicações para novas pesquisas a partir das investigações do GT04. In: SEMINÁRIO INTERNACIONAL DE PESQUISA EM EDUCAÇÃO MATEMÁTICA, 7. 2018, Foz do Iguaçu. Anais[...] Foz do Iguaçu: SBEM, 2018. p. 1-11.

BIANCHINI, B. L.; LIMA, G. L.; GOMES, E. Formação de professor: reflexões da Educação Matemática no Ensino Superior. Educação e Realidade. Porto Alegre, v. 44, n. 1, p. 1-22, 2019 a.

BIANCHINI, B. L.; LIMA, G. L.; GOMES, E. Possibilidades de novas pesquisas em Cálculo, Análise e Álgebra Linear a partir de um mapeamento das investigações do GT04. REnCiMa. São Paulo, v. 10, n. 2, p. 112-124, 2019b.

BIANCHINI, B. L.; LIMA, G. L.; GOMES, E. Linear algebra in engineering: an analysis of Latin American studies. ZDM Mathematics Education 51, Karlsruhe - Alemanha, v. 7, p. 1097-110, 2019c. https://doi.org/10.1007/s11858-019-01081-5

ELIAS, H. R.; BARBOSA, L. N. S. C.; SAVIOLI, A. M. P. D. Indícios de dificuldade na compreensão da Matemática avançada: o conceito de grupo. In: SEMINÁRIO INTERNACIONAL DE PESQUISA EM EDUCAÇÃO MATEMÁTICA, 5., 2012, Petrópolis. Anais[...] Petrópolis: SBEM, 2012. p. 1-17.

FIGUEIREDO, A. C. Saberes e Concepções de Educação Algébrica em um curso de Licenciatura em Matemática. 2007. Tese (Doutorado em Educação Matemática) - Programa de Estudos PósGraduados em Educação Matemática, Pontifícia Universidade Católica de São Paulo, São Paulo, 2007.

FIORENTINI, D.; MIORIN, M.A.; MIGUEL, A. A. Contribuição para um repensar a Educação Algébrica Elementar. Pro-Posições. Campinas, v. 1, n. 10, 1993.

FREUDENTHAL, H. What is Algebra and What has it been in History? Archive for History of Exact Sciences, Paris, v. 16, n. 3, p. 189-200, 1977.

FROTA, M. C. R.; NASSER, L. (Org.). Educação Matemática no Ensino Superior: pesquisas e debates. Brasília: SBEM, 2009.

FROTA, M. C. R.; BIANCHINI, B. L.; CARVALHO, A. M. T. (Orgs.). Marcas da Educação Matemática no Ensino Superior. Campinas: SBEM/Papirus, 2013.

GARCIA, R.; PIAGET, J. Psychogenesis and the history of science. $1^{\text {a }}$ ed. New York: Columbia University Press, 1989.

JONES, L. Algebra in the primary school. Education 3-13, Cheadle, v. 21, n. 2, p. 27-31, 1993.

KIRNEV, D. C. B.; SAVIOLI, A. M. P. D. Set-befores e Met-befores: influência no estudo de anéis de polinômios. VIDYA, Santa Maria, v. 37, n. 2, p. 533-547, 2017.

KLUTH, V. S. Uma visão filosófica do pensar algébrico. In: ENCONTRO NACIONAL DE 
EDUCAÇÃO MATEMÁTICA, 8., 2019, Recife. Anais [...] Recife: SBEM, 2004. p. 1-14. LEE, L. Early - but which algebra? The future of the teaching and learning of algebra. In: ICMI STUDY CONFERENCE, 12., 2001, Melbourne (Australia). Proceedings [...] Melbourne: ICMI, 2001. v. 2, p. 392-300.

LIMA, G. L., BIANCHINI, B. L., GOMES, E. Cálculo e Análise: mapeamento das pesquisas do GT04 - Educação Matemática no Ensino Superior. VIDYA, Santa Maria, v. 37, n. 2, p. 314-334, 2017.

LIMA, G. L., BIANCHINI, B. L., GOMES, E. Ensino e Aprendizagem de Álgebra Linear. Educação Matemática em Revista. Brasília, v. 24, n. 62, p. 140-154, abr.jun. 2019.

LINS, R.C.; GIMENEZ, J. Perspectivas em aritmética e álgebra para o século XXI, $1^{\mathrm{a}}$ ed. São Paulo: Papirus, 1997.

MALISANI, E. Los obstaculos epistemologicos en el desarrollo del pensamiento algebraico: vision histórica. Argentina: Revista IRICE, 1999.

MONDINI, F.; BICUDO, M. A. V. A presença da Álgebra nos cursos de Licenciatura em Matemática no Estado do Rio Grande do Sul. Acta Scientiae, Canoas, v. 12, n. 2, p. 43-54, jul./dez. 2010.

MOSES, B. Exploring our world through algebraic thinking. Mathematics Education Dialogues. Reston, v. 3, n. 2, p. 1-17, 2000.

RADFORD, L. G. The historical origins of algebraic thinking. In: SUTHERLAND, R. et al. (Eds.). Perspectives on school algebra. Dordrecht: Springer, 2001, p. 13-36.

SAVIOLI, A. M. P. D. Equações Algébricas nas Práticas Vivenciadas: uma abordagem histórica. In: SEMINÁRIO INTERNACIONAL DE PESQUISA EM EDUCAÇÃO MATEMÁTICA, 3., 2006, Curitiba. Anais [...] Curitiba: SBEM, 2006. p. 1-09.

SAVIOLI, A. M. P. D. Origens e caracterizações da Álgebra e do Pensamento Algébrico sob a ótica de vários autores. In: SEMINÁRIO INTERNACIONAL DE PESQUISA EM EDUCAÇÃO MATEMÁTICA, 4., 2019, Taguatinga. Anais [...] Taguatinga: SBEM, 2009. p. 1-17.

SEVERINO, A. J. Metodologia do trabalho científico. 23. ed. São Paulo: Cortez, 2007.

SFARD, A. The Development of Algebra: Confronting Historical and Psychological Perspectives. Journal of Mathematical Behavior, Syracuse, v. 14, p. 15-39, 1995.

UNGURU, S. On the need to rewrite the history of Greek mathematics. Archive for History of Exact Sciences, Paris, v. 5, p. 67-114, 1975.

USISKIN, Z. Concepções da álgebra da escola média e utilizações das variáveis. In: COXFORD, A. F.; SHULTE, A. P. (Orgs.). As idéias da álgebra. São Paulo: Atual, 1995.

Submetido em 09 de Julho de 2020. Aprovado em 22 de Dezembro de 2020. 